\title{
Rancang Bangun Aplikasi Pencarian Rumah Ibadah Di Kotamobagu Berbasis Android
}

\author{
Andri Novriadi Lomboan ${ }^{1)}$, Dringhuzen J. Mamahit ${ }^{2}$, Yaulie Deo. Y. Ridengan ${ }^{3)}$ \\ Program Studi Teknik Informatika, Fakultas Teknik, Universitas Sam Ratulangi Manado \\ andrinovriadi@gmail.com ${ }^{1)}$,dringhuzen.mamahit@gmail.com ${ }^{2}$, rindengan@unsrat.ac.id ${ }^{3}$ )
}

\begin{abstract}
Abstrak-Rumah Ibadah merupakan sesuatu yang dibutuhkan oleh seluruh umat beragama untuk dapat melakasanakan peribadatan menurut agama dan keperacayaan yang dianut oleh masingmasing orang. Begitu pula mengenai Informasi rumah ibadah. Dibutuhkan informasi yang dapat diperoleh dengan cepat dan akurat. Untuk menjawab kebutuhan masyarakat, maka dibutuhkan sebuah aplikasi yang dapat menyediakan semua informasi itu. Client aplikasi ini dibuat berbasis Android yang terhubung dengan layanan google maps. Sehingga masyarakat yang menggunakan smartphone Android dapat dengan mudah memperoleh semua inforamasi itu karena informasi mengenai lokasi yang ditampilkan dalam bentuk peta digital. Dalam penelitian ini menggunakan metode DAD (Disciplined Agile Delivery). Metode DAD terdiri dari 3 fase yaitu fase inception, fase construction dan fase transition. Berdasarkan dengan hasil penelitian ini dapat disimpulkan bahwa aplikasi dapat membantu masyarakat dalam memperoleh sebuah informasi dengan cepat dan akurat. Selain itu aplikasi ini juga membantu pihak lain untuk memperoleh data yang akurat yang dapat diolah berdasarkan kebutuhan dari pengguna.
\end{abstract}

Kata kunci : Android,DAD (Disciplined Agile Dlivery), google maps, Rumah Ibadah.

Abstrack- The House of Worship is something that is needed by all religious people to be able to carry out worship according to religion and the beliefs adhered to by each person. Likewise regarding information on places of worship. Information that can be obtained quickly and accurately is needed. To answer the needs of the community, an application that can provide all that information is needed. This client application is made based on Android that is connected to google maps service. So that people who use Android smartphones can easily get all the information because information about the location displayed in the form of a digital map. In this study using the DAD (Disciplined Agile Delivery) method. The DAD method consists of 3 phases: inception phase, construction phase and transition phase. Based on the results of this study it can be concluded that the application can help people to obtain information quickly and accurately. Besides this application also helps other parties to obtain accurate data that can be processed based on the needs of users.

Keywords: Android, DAD (Disciplined Agile Dlivery), google maps, House of Worship.

\section{PENDAHULUAN}

Seiring perkembangan teknologi yang semakin pesat, kini segala sesuatu dituntut agar bisa lebih cepat dan mudah. Begitupun halnya bagaimana kita bisa memperoleh sebuah informasi. Kita pasti sangat ingin agar informasi yang kita butuhkan itu dapat diperoleh secara mudah dan cepat. Dikarenakan informasi merupakan salah satu kebutuhan masyarakat yang paling utama. Salah satu media yang dapat menjadi fasilitas untuk mendapatkan informasi secara cepat dan tepat adalah internet. Internet merupakan sebuah wadah untuk manusia agar secara mudah bisa memperoleh sebuah informasi yang diinginkan. Hal ini dimanfaatkan oleh para produsen smartphone untuk berlomba-lomba membuat sebuah alat bantu komunikasi yang sangat praktis dan fleksibel yaitu smartphone untuk menciptakan ataupun mengembangkan aplikasi yang baru. Keberadaan smartphone sekarang sangatlah penting bagi para pengguna untuk mendapatkan informasi dan memenuhi berbagai kebutuhannya secara lebih cepat dan mudah. Sehingga tidak heran lagi di zaman sekarang banyak orang-orang yang menggunakan smartphone dalam kegiatan sehari-hari mereka sebagai alat bantu yang bisa digunakan kapanpun dan dimanapun.

Kota Kotamobagu hingga saat ini masih sebagai daerah yang tergolong baru dan dalam masa proses berkembang sehingga banyak mengundang para investor asing maupun lokal untuk berinvestasi di Kota Kotamobagu, secara otomatis banyak lapangan pekerjaan yang terbuka yang mengundang banyak orang datang untuk mencari pekerjaan. Dan dari segi pendidikan, Kota Kotamobagu memiliki beberapa Universitas dan Sekolah yang baru, baik dari tingkat dasar maupun sampai tingkat SMA sederajat yang baru dibuka hal ini juga mengundang orang-orang yang berada di daerah sekitar Kota Kotamobagu datang untuk menimbah ilmu sebagai pelajar di salah satu sekolah maupun sebagai mahasiswa di salah satu perguruan tinggi yang ada di Kota Kotamobagu. Sebagai orang baru di Kota Kotamobagu tentunya mereka membutuhkan informasi lokasi tempat ibadah untuk mereka beribadah. Dengan kebutuhan rohani dari para pendatang baru yang sangat besar akan mencari tempat ibadah, maka informasi pencarian tempat ibadah dirasa sangatlah penting untuk membantu para pendatang baru maupun masyarakat yang kebingungan mencari tempat ibadah di sekitar Kota Kotamobagu dan tentunya dapat diakses dengan menggunakan smartphone berbasis platform android.

Oleh karena itu, berdasarkan uraian latar belakang tersebut membuat penulis berinisiatif untuk membuat sebuah Aplikasi Pencarian Rumah Ibadah Berbasis Android, yang dapat memberikan sebuah informasi secara detail mengenai lokasi rumah-rumah ibadah yang ada di Kota Kotamobagu. Aplikasi android berbasis multiplatform yang dapat membantu para pendatang mencari rumah ibadah yang ada disekitar mereka tinggal dengan menggunakan aplikasi Android untuk 
memberikan letak serta menunjukan lokasi rumah ibadah di mobile phone yang tentunya terkoneksi dengan internet.

\section{A. Rumah Ibadah}

Rumah ibadah merupakan tempat beribadah bagi setiap orang yang beragama. Rumah ibadah sendiri terdiri dari beberapa menurut kepercayaan yang dianut oleh masing-masing orang. Di Indonesia sendiri ada 6 agama yang saat ini diakui oleh pemerintah yang terdiri dari Kristen,Islam,Katolik,Hindu,Budha dan Konghucu. Dari ke 6 agama tersebut memiliki rumah ibadah yang terdiri dari:
1) Gereja : Gereja adalah tempat ibadah bagi pemeluk agama Kristen Protestan.
2) Masjid : Masjid adalah tempat ibadah bagi masyarakat penganut agama Islam.
3) Gereja/Kapel : Gereja/Kapel adalah tempat ibadah bagi
pemeluk agama Katolik.
4) Pura : Pura adalah tempat ibadah bagi pemeluk
4) Pura
5) Vihara : Vihara adalah tempat ibadah bagi pemeluk agama Budha.
6) Kelenteng : Kelenteng merupakan tempat beribadah bagi pemeluk agama Konghucu.

\section{B. Android}

${ }^{[6]}$ Android adalah sistem operasi berbasis Linux yang dirancang untuk perangkat seluler layar sentuh seperti ponsel pintar (smartphone) dan komputer tablet. Android awalnya dikembangkan oleh Android, Inc, dengan dukungan finansial dari Google, yang kemudian membelinya pada tahun 2005. Sistem dirilis secara resmi pada tahun 2007, bersamaan dengan didirikan Open Handset Alliance, konsorsium dari perusahaanperusahaan perangkat keras, perangkat lunak dan telekomunikasi yang bertujuan untuk memajukan standar terbuka perangkat seluler. Ponsel android pertama mulai dijual pada bulan oktober 2008.

Android adalah sistem operasi dengan sumber terbuka, dan Google merilis kodenya di bawah Lisensi Apache. Kode dengan sumber terbuka dan lisensi perizinan pada Android memungkinkan perangkat lunak untuk dimodifikasi secara bebas dan didistribusikan oleh para pembuat perangkat, operator nirkabel, dan pengembang aplikasi. Selain itu, Android memiliki sejumlah besar komunitas pengembang aplikasi (apps) yang memperluas fungsionalitas perangkat, umumnya ditulis dalam versi kustomisasi bahasa pemrograman Java. Pada bulan Oktober 2013, ada lebih dari satu juta aplikasi yang tersedia untuk Android, dan sekitar 50 miliar aplikasi telah diunduh dari Google Play, toko aplikasi utama Android. Sebuah survei pada bulan April-Mei 2013 menemukan bahwa Android adalah platform paling populer bagi para pengembang, digunakan oleh $71 \%$ pengembang aplikasi bergerak. Di Google I/O 2014, Google melaporkan terdapat lebih dari satu miliar pengguna aktif bulanan Android, meningkat dari 583 juta pada bulan Juni 2013.

Android juga menjadi pilihan bagi perusahaan teknologi yang menginginkan sistem operasi berbiaya rendah, bisa dikustomisasi, dan ringan untuk perangkat berteknologi tinggi tanpa harus mengembangkannya dari awal.

\section{Google Maps}

Google Maps adalah layanan pemetaan web yang dikembangkan oleh Google. Layanan ini memberikan citra satelit, peta jalan, panorama $360^{\circ}$, kondisi lalu lintas, dan perencanaan rute untuk bepergian dengan berjalan kaki, mobil, sepeda (versi beta), atau angkutan umum.

Google Maps dimulai sebagai program desktop $\mathrm{C}++$, dirancang oleh Lars dan Jens Eilstrup Rasmussen pada Where 2 Technologies. Pada Oktober 2004, perusahaan ini diakuisisi oleh Google, yang diubah menjadi sebuah aplikasi web. Setelah akuisisi tambahan dari perusahaan visualisasi data geospasial dan analisis lalu lintas, Google Maps diluncurkan pada Februari 2005. Layanan ini menggunakan Javascript, XML, dan AJAX. Google Maps menawarkan API yang memungkinkan peta untuk dimasukkan pada situs web pihak ketiga, dan menawarkan penunjuk lokasi untuk bisnis perkotaan dan organisasi lainnya di berbagai negara di seluruh dunia. Google Map Maker memungkinkan pengguna untuk bersama-sama mengembangkan dan memperbarui pemetaan layanan di seluruh dunia.

\section{GPS}

GPS adalah singkatan dari Global Positioning System, yang merupakan sistem navigasi dengan menggunakan teknologi satelit yang dapat menerima sinyal dari satelit. Sistem ini menggunakan 24 satelit yang mengirimkan sinyal gelombang mikro ke bumi. Sinyal ini diterima oleh alat penerima (receiver) di permukaan, dimana GPS receiver ini akan mengumpulkan informasi dari satelit GPS seperti:

1) Waktu. GPS receiver menerima informasi waktu dari jam atom yang mempunyai keakurasian sangat tinggi.

2) Lokasi. GPS memberikan informasi lokasi dalam tiga dimensi:
a) Latitude
b) Longitude
c) Elevasi

3) Kecepatan. Ketika berpindah tempat, GPS dapat menunjukkan informasi kecepatan berpindah tersebut.

4) Arah perjalanan. GPS dapat menunjukkan arah tujuan.

5) Simpan lokasi. Tempat-tempat yang sudah pernah atau ingin dikunjungi bisa disimpan oleh GPS receiver.

6) Komulasi data. GPS receiver dapat menyimpan informasi track, seperti total perjalanan yang sudah pernah dilakukan, kecepatan rata-rata, kecepatan paling tinggi, kecepatan paling rendah, waktu/jam sampai tujuan, dan sebagainya.

\section{E. Aplikasi}

${ }^{[6]}$ Aplikasi adalah Perangkat lunak aplikasi (bahasa Inggris: software application) adalah suatu subkelas perangkat lunak computer yang memanfaatkan kemampuan computer langsung untuk melakukan suatu tugas yang diinginkan pengguna. Biasanya dibandingkan dengan perangkat lunak system yang mengintegrasikan berbagai kemampuan computer, tapi tidak secara langsung menerapkan kemampuan tersebut untuk mengerjakan suatu tugas yang menguntungkan pengguna.

Contoh utama perangkat lunak aplikasi adalah pengolah kata, lembar kerja, dan pemutar media. Beberapa Aplikasi yang digabung bersama menjadi suatu paket kadang disebut sebagai suatu paket atau suite aplikasi (application suite). sehingga 
memudahkan pengguna untuk mempelajari dan menggunakan tiap aplikasi.

\section{F. Sistem Informasi Geografis}

${ }^{[9]}$ Sistem Informasi Geografis (SIG) adalah sistem yang terdiri dari perangkat keras, perangkat lunak, data, manusia (brainware), organisasi dan lembaga yang digunakan untuk mengumpulkan, menyimpan, menganalisis, dan menyebarkan informasi-informasi mengenai daerah-daerah di permukaan bumi.

Sistem Informasi Geografis/GIS (Geogrphic Information System) merupakan bentuk cara penyajian informasi terkait dengan objek berupa wilayah dalam bentuk informasi spatial (Keruangan).

SIG mempunyai kemampuan untu menghubungkan berbagai data pada suatu titik tertent di bumi,menggabungkannya, menganalisa dan akhirnya memetahkan hasilnya. Data yang diolah pada SIG adalah data spatial yaitu sebuah data yang berorientasi geografis dan merupakan lokasi yang memiliki sistem kordinat tertentu, sebagai dasar referensinya. Sehingga aplikasi SIG dapat menjawab beberapa pertanyaan seperti lokasi, kondisi, tren, pola, dan pemodelan. Kemampuan inilah yang membedakan SIG dengan sistem informasi lainnya.

\section{II.METODOLOGI PENELITIAN}

Pada bab ini menjelaskan mengenai metode yang digunakan untuk penelitian ini dimana terdapat alur rincian tentang bahan atau materi,lokasi, alat, urutan langkah-langkah,maupun metode yang dipakai dalam penelitian ini yang dibuat secara sistematis, sehingga mudah untuk menyelesaikan permasalahan dan kesulitan yang dihadapi.

\section{A. Objek dan Lokasi Penelitian}

Adapun penelitian yang dilakukan untuk menyusun Tugas Akhir ini di laksanakan di ruang lingkup daerah Kota Kotamobagu.

\section{B. Metode Pengembangan Sistem}

${ }^{[5]}$ Penulis memilih menggunakan Metode Disciplined Agile Delivery karena dengan metode ini, perancangan dan pembangunan aplikasi ini dapat memenuhi kebutuhan pengguna secara tepat dan dapat diselesaikan dengan waktu yang relatif singkat dengan fleksibilitasnya sesuai dengan kelebihankelebihan yang ditawarkan oleh metode DAD.

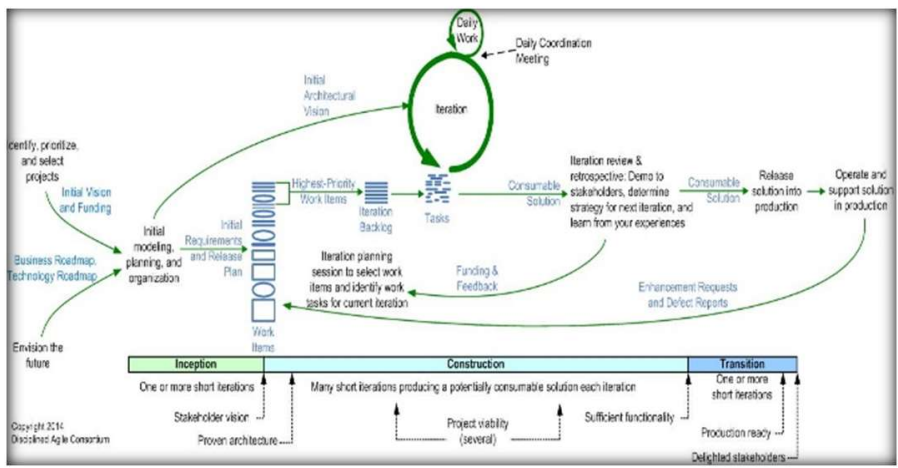

Gambar 1. Tahapan Metodologi Disciplined Delivery
Metode DAD terdiri dari 3 fase pengembangan yaitu Fase Inception, Fase Construction, dan Fase Transition.

1) Fase Inception

Pada fase ini merupakan fase awal perancangan sistem yang mengumpulkan semua kebutuhan-kebutuhan yang akan digunakan dalam mengembangkan sistem. Dokumen yang dihasilkan dalam fase ini diantaranya adalah dokumen Vision, dokumen Supplementary Specification dan software Project Plan.

\section{2) Fase Construction}

Pada fase ini kegiatan yang dilakukan antara lain memodelkan, membangun sistem dan membuat dokumentasi Suplementary Requirements Spesification (SRS), Software Architecture Document (SAD). Diagram dan Deployment View

\section{3) Fase Transition}

Meliputi aktifitas me-review kembali sistem aplikasi dan menginstalasi sistem aplikasi. Dokumen yang dihasilkan adalah user manual dan Instalation Manual.

\section{HASIL DAN PEMBAHASAN}

Pada bagian pembahasan, penulis akan menampilkan setiap artifak terkait dari setiap proses dan aktivitas yang dilakukan pada setiap fase menurut metodologi DAD. Setiap fase memiliki tujuan aktivitas proses, dimana aktivitas proses tersebut menghasilkan artifak atau dokumentasi aplikasi yang dibangun. Seperti yang disebutkan diatas, DAD membagi tahapan pengembangan piranti lunak menjadi inception, construction dan transition.

A. Fase Inception

Pada fase ini merupakan fase awal perancangan sebuah sistem yang mengumpulkan semua kebutuhan-kebutuhan yang nantinya akan digunakan dalam pengembangan sistem.

1) Tentang Produk

\begin{tabular}{|l|l}
\hline \multicolumn{1}{c}{ TABEL I. MASALAH YANG DIHADAPI } \\
\hline \hline Masalah : & $\begin{array}{l}\text { Masyarakat tidak } \\
\text { mengetahui lokasi Rumah } \\
\text { Ibadah yang ada di Kota } \\
\text { Kotamobagu secara detail. }\end{array}$ \\
\hline Menyebabkan : & $\begin{array}{l}\text { Proses untuk mengetahui } \\
\text { lokasi Rumah Ibadah } \\
\text { memakan waktu yang } \\
\text { banyak. }\end{array}$ \\
\hline $\begin{array}{l}\text { Dampak yang } \\
\text { ditimbulkan : }\end{array}$ & $\begin{array}{l}\text { Lamanya memperoleh } \\
\text { sebuah Informasi }\end{array}$ \\
\hline $\begin{array}{l}\text { Solusi yang } \\
\text { diimplemantasikan : }\end{array}$ & $\begin{array}{l}\text { Aplikasi yang dapat } \\
\text { memberikan informasi } \\
\text { secara detail dan dapat } \\
\text { diakses dimana saja. }\end{array}$ \\
\hline
\end{tabular}


2) Penggunaan Produk

TABEL 2. TENTANG PENGGUNAAN PRODUK

\begin{tabular}{|ll}
\hline \hline Untuk : & $\begin{array}{l}\text { Masyarakat yang ada di } \\
\text { Kota Kotamobagu }\end{array}$ \\
\hline Bertanggung jawab untuk : & $\begin{array}{l}\text { Memberikan informasi } \\
\text { mengenai lokasi Rumah- } \\
\text { rumah Ibadah yang ada di } \\
\text { Kota Kotamobagu }\end{array}$ \\
\hline Sistem : & $\begin{array}{l}\text { Sebuah sistem aplikasi } \\
\text { berbasis Andorid }\end{array}$ \\
\hline Berfungsi untuk : & $\begin{array}{l}\text { Mempermudah masyarakat } \\
\text { dalam mendapatkan } \\
\text { Informasi mengenai lokasi } \\
\text { dari Rumah Ibadah yang } \\
\text { ada di Kota Kotamobagu } \\
\text { Merupakan suatu } \\
\text { purwarupa atau bentuk } \\
\text { awal dari sebuah aplikasi } \\
\text { yang dapat dikembangkan } \\
\text { selanjutnya }\end{array}$ \\
\hline \hline
\end{tabular}

TABEL 3. TENTANG PENGGUNA

\begin{tabular}{llll}
\hline \hline Nama & Keterangan & \multicolumn{1}{c}{$\begin{array}{c}\text { Tanggung } \\
\text { Jawab }\end{array}$} & Stakeholder \\
Admin & $\begin{array}{l}\text { Admin } \\
\text { Menangani } \\
\text { manajemen } \\
\text { data }\end{array}$ & $\begin{array}{l}\text { manajemen } \\
\text { data }\end{array}$ & - \\
User & - & $\begin{array}{l}\text { Menerima } \\
\text { data lokasi } \\
\text { Rumah Ibadah }\end{array}$ & - \\
& & \\
\hline
\end{tabular}

TABEL I Menjelaskan mengenai Masalah yang dihadapi.dalam pengembangan produk.

TABEL II menjelaskan mengenai penggunaan produk dalam Aplikasi Pencarian Rumah Ibadah Berbasis Android.

TABEL III menjelaskan mengenai pengguna dari aplikasi yang terdiri dari admin dan user.Dimana admin berperan menangani manajemen data aplikasi sedangkan user hanya sebagai penerima data lokasi rumah ibadah.

\section{2). Lingkungan Pengguna}

Di jaman ini perkembangan smartphone sudah sangat pesat yang dibarengi dengan tingkat penggunaan smartphone sudah sangat luas. Dalam penggunaan aplikasi ini dibutuhkan koneksi internet agar dapat mengakses aplikasi pencarian rumah ibadah ini.

\section{B. Fase Construction}

Pada fase ini kegiatan yang dilakukan antara lain memodelkan, membangun sistem dan membuat dokumentasi,

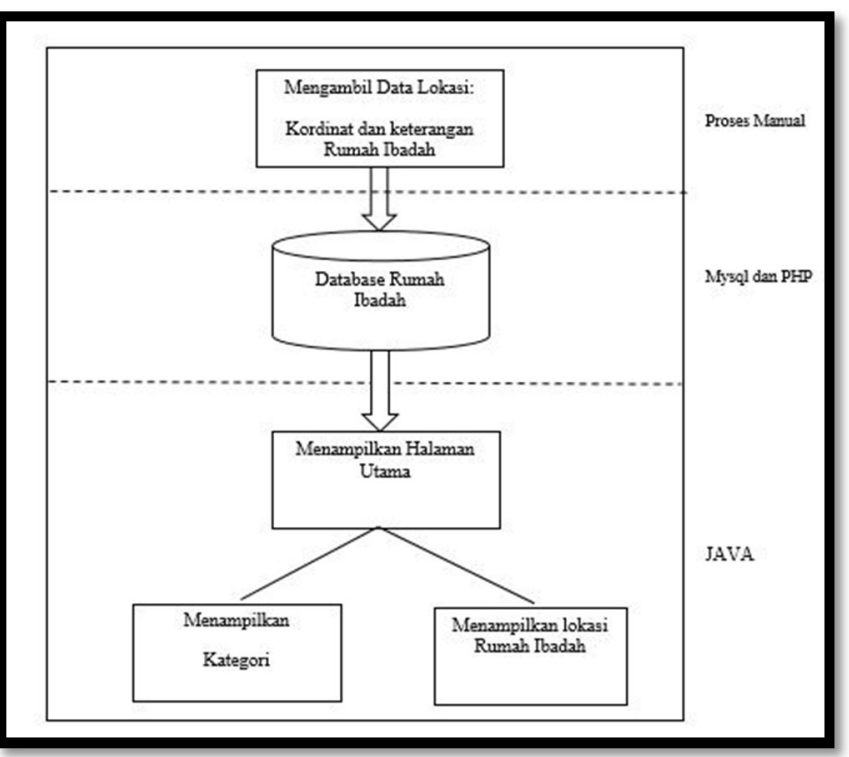

Gambar 2. Arsitektur Sistem Aplikasi
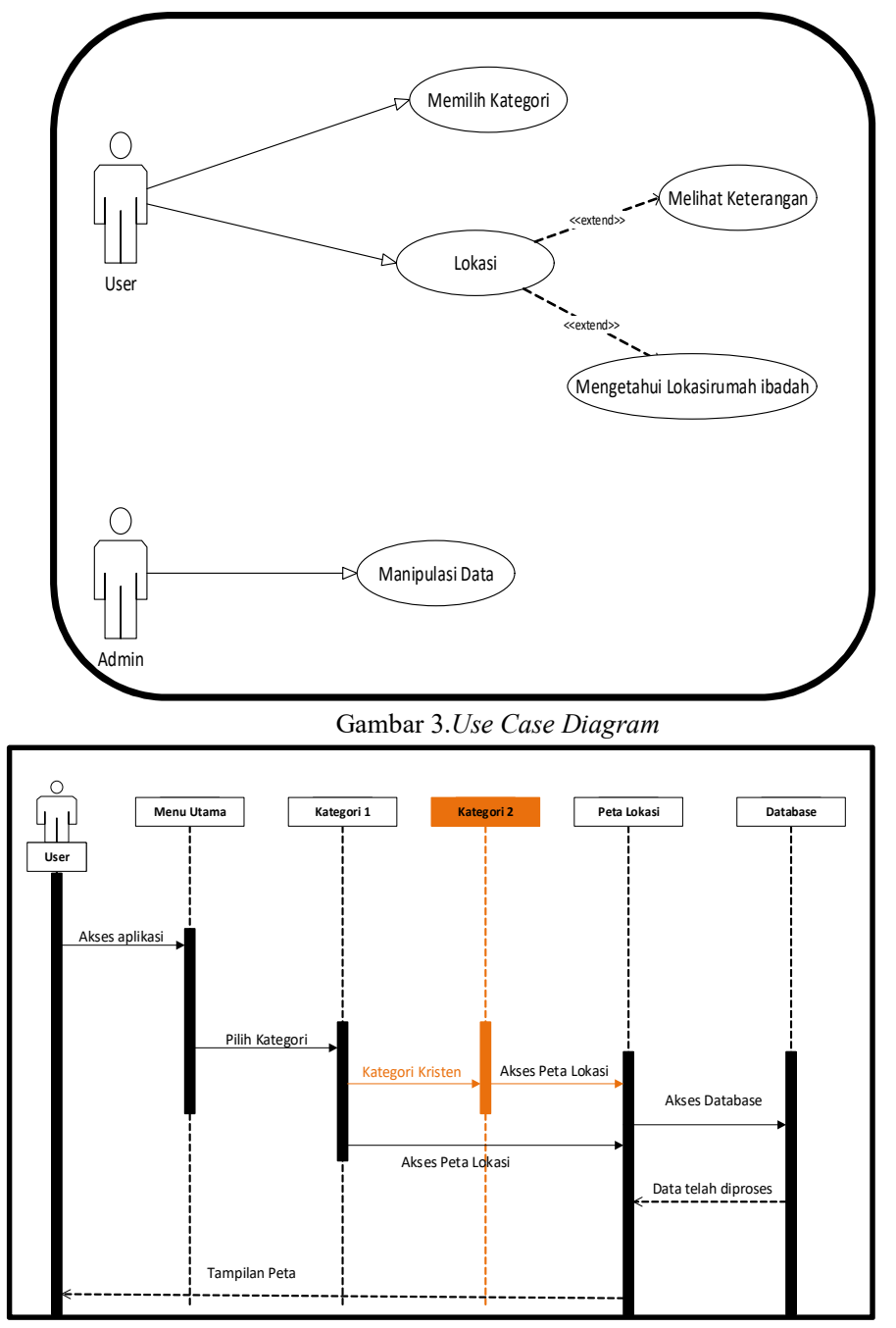

Gambar 4. Sequence Diagram

Diagram-diagram yang dihasilkan adalah Use Case Diagram, Sequence Diagram, dan Deyployment View. 
Gambar 2 dapat kita lihat bahwa aplikasi ini dirancang meliputi 3 bagian yaitu proses manual dalam pengambilan data lokasi maupun informasi rumah ibadah,untuk MySQL dan PHP melakukan dalam pengolahan database server dari rumah ibadah dan untuk pembuatan aplikasi client sendiri dibuat untuk user yang ditulis dalam bahasa pemrograman $J A V A$.

Gambar 3 Use Case diagram yang dijelaskan pada tahap ini merupakan use case diagram dari aplikasi client. Dalam use case diagram ini terdapat 2 aktor yaitu user dan admin .

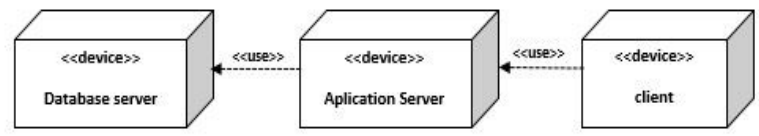

Gambar 5. Deployment Diagram

1). Use Case Description

Use case description akan menjelaskan tentang isi dari use case diagram.

2). Tabel Use Case Description

TABEL IV. USE CASE DESCRIPTION MEMILIH KATEGORI

\begin{tabular}{ll}
\hline \hline Title: & Memilih Kategori \\
\hline Description: & User memilih kategori \\
\hline Primary Actor: & User \\
\hline Preconditions: & $\begin{array}{l}\text { User sudah telah berhasil } \\
\text { membuka aplikasi }\end{array}$ \\
\hline Postconditions: & $\begin{array}{l}\text { User berhasil memilih kategori } \\
\text { Main Success Scenario: }\end{array}$ \\
$\begin{array}{l}\text { 1. User membuka aplikasi } \\
\text { 2. Sistem akan } \\
\text { menampilkan halaman } \\
\text { kategori }\end{array}$ \\
\hline Extension: & 3. User memilih kategori \\
\hline Frequency of Use: & $\begin{array}{l}\text { Setiap kali user membuka } \\
\text { aplikasi }\end{array}$ \\
\hline \hline
\end{tabular}

TABEL V. USE CASE DESCRIPTION MELIHAT LOKASI

\begin{tabular}{|c|c|}
\hline Title: & Lokasi \\
\hline Description: & $\begin{array}{l}\text { User melihat lokasi berdasarkan } \\
\text { kategori yang dipilih }\end{array}$ \\
\hline Primary Actor: & User \\
\hline Preconditions: & User sudah memilih kategori \\
\hline Postconditions: & User memilih lokasi \\
\hline $\begin{array}{l}\text { Main Success } \\
\text { Scenario: }\end{array}$ & $\begin{array}{l}\text { 1. User memilih kategori } \\
\text { 2. User melihat lokasi rumah ibadah } \\
\text { 3. User melihat keterangan rumah } \\
\text { ibadah }\end{array}$ \\
\hline Extension: & - \\
\hline Frequency of Use: & $\begin{array}{l}\text { Setiap kali user melihat lokasi rumah } \\
\text { ibadah }\end{array}$ \\
\hline
\end{tabular}

TABEL VI. USE CASE DESCRIPTION MELIHAT KETERANGAN

\begin{tabular}{|c|c|}
\hline Title: & Melihat Keterangan \\
\hline Description: & $\begin{array}{l}\text { User melihat keterangan rumah ibadah } \\
\text { yang telah dipilih oleh } u \text { ser }\end{array}$ \\
\hline Primary Actor: & User \\
\hline Preconditions: & - \\
\hline Postconditions: & Berhasil memilih kategori \\
\hline $\begin{array}{l}\text { Main Success } \\
\text { Scenario: }\end{array}$ & $\begin{array}{l}\text { 1. User memilih button kategori } \\
\text { yang dipilih } \\
\text { 2. User memilih tanda letak lokasi } \\
\text { 3. User melihat keterangan dari } \\
\text { rumah ibadah }\end{array}$ \\
\hline
\end{tabular}

\section{Extension:}

Frequency of Use: Pilihan tidak ditampilkan

1. User memeriksa koneksi internet

2. User me-restart aplikasi

TABEL VII. USE CASE DESCRIPTION MENGETAHUI LOKASI

\begin{tabular}{|c|c|}
\hline Title: & Mengetahui lokasi \\
\hline Description: & $\begin{array}{l}\text { User bisa mengetahui lokasi rumah } \\
\text { ibadah }\end{array}$ \\
\hline Primary Actor: & User \\
\hline Preconditions: & - \\
\hline Postconditions: & Berhasil memilih kategori \\
\hline $\begin{array}{l}\text { Main } \\
\text { Success }\end{array}$ & $\begin{array}{l}\text { 1. User memilih button kategori yang } \\
\text { dipilih }\end{array}$ \\
\hline Scenario: & $\begin{array}{l}\text { 2. User memilih button gps } \\
\text { 3. User melihat keterangan rumah } \\
\text { ibadah }\end{array}$ \\
\hline Extension: & $\begin{array}{l}\text { Tidak dapat melihat lokasi } \\
\text { 1. User memeriksa koneksi internet }\end{array}$ \\
\hline $\begin{array}{l}\text { Frequency of } \\
\text { Use: }\end{array}$ & $\begin{array}{l}\text { Setiap kali akan melihat lokasi rumah } \\
\text { ibadah }\end{array}$ \\
\hline
\end{tabular}

TABEL VIII. USE CASE DESCRIPTION MANIPULASI DATA

\begin{tabular}{|c|c|}
\hline Title: & Manipulasi Data \\
\hline Description: & Memanipulasi data rumah ibadah \\
\hline Primary Actor: & Admin \\
\hline Preconditions: & - \\
\hline Postconditions: & Membuka "http://rumah-ibadah.tk" \\
\hline $\begin{array}{l}\text { Main } \\
\text { Success Scenario: }\end{array}$ & $\begin{array}{l}\text { 1. Memanipulasi data (melihat, } \\
\text { menginput, mengedit dan } \\
\text { menghapus data) }\end{array}$ \\
\hline Extension: & $\begin{array}{l}\text { Tidak dapat membuka form } a d m i n \\
\text { 1. Mengecek koneksi internet }\end{array}$ \\
\hline
\end{tabular}

Frequency of Use: Setiap kali akan memanipulasi data 
TABEL IV menjelaskan kondisi ketika memilih kategori. User dapat memilih kategori ketika user telah berhasil membuka aplikasi, sistem akan menampilkan halaman utama dan user dapat memilih kategori.

TABEL V menjelaskan kondisi ketika melihat lokasi. User dapat melihat lokasi ketika user telah berhasil memilih kategori yang diinginkan, sistem akan menampilkan titik-titik lokasi rumah ibadah berdasarkan kategori yang sudah dipilih. Pada halaman lokasi ini ada beberapa fitur yang telah disediakan yaitu kita dapat melihat informasi dari rumah ibadah yang dipilih.

TABEL VI menjelaskan kondisi saat user melihat keterangan. User dapat melihat keterangan ketika user telah berhasil masuk pada halaman peta. Apabila user ingin melihat keterangan, user dapat memilih salah satu tanda lokasi kemudian sistem akan menampilkan keterangan..

TABEL VII menjelaskan kondisi ketika mengetahui lokasi. User dapat mengetahui lokasi rumah ibadah ketika user telah masuk pada halaman peta. Apabila user ingin mengetahui lokasi rumah ibadah, user dapat dapat memilih salah satu simbol gps. Maka sistem akan menunjukan lokasi rumah ibadah.

TABEL VIII menjelaskan kondisi saat admin melakukan manipulasi data. Untuk melakukan manipulasi data, dapat mengakses url http://rumah-ibadah.tk. Dapat melihat, menginput, mengedit atau menghapus data apabila tidak dapat membuka form maka admin dapat mengecek koneksi internet.

Gambar 4 Sequence Diagram pada gambar 4 memberikan sebuah gambaran mengenai apa yang akan dilakukan dalam aplikasi. Aplikasi yang dimaksudkan dalam sequence diagram ini merupakan sebuah aplikasi client yang dibuat dengan berbasis android.

Gambar 5 Pada Design Physical Layer Architecture dijelaskan menggunakan Deployment Diagram. Deployment Diagram menjelaskan bagaimana hubungan antara perangkat keras serta perangkat lunak dalam sistem dan distribusi fisik dari pengolahan sistem.

\section{1) Storyboard}

TABEL IX sampai dengan XII menunjukan Storyboard dari Aplikasi pencarian rumah ibadah Berbasis Android yang memiliki 4 tampilan.

TABEL IX. STORYBOARD TAMPILAN AWAL APLIKASI

\begin{tabular}{ll}
\hline SCENE & \multicolumn{1}{c}{ DESKRIPSI } \\
Berikut ini adalah tampilan \\
SplashScreen dari Aplikasi \\
pencarian rumah ibadah yang \\
berisi logo aplikasi serta \\
penjelasan singkat mengenai \\
aplikasi ini.akan muncul setelah \\
user membuka aplikasi.
\end{tabular}

\section{Fase Transition}

Meliputi aktifitas me-review kembali sistem aplikasi dan menginstalasi sistem aplikasi. Dokumen yang dihasilkan adalah user manual dan Instalation Manual.

TABEL X. STORYBOARD TAMPILAN UTAMA APLIKASI

\begin{tabular}{ll}
\hline SCENE & \multicolumn{1}{c}{ DESKRIPSI } \\
Pada gambar ini dapat \\
kita lihat bahwa ada 6 fitur \\
yang ditampilkan pada \\
halaman menu utama yang \\
terdiri dari fitur Islam, fitur \\
Kristen, fitur Katolik, fitur \\
Hindu, fitur Budha, fitur \\
Konghucu
\end{tabular}

TABEL XI. STORYBOARD TAMPILAN LOKASI

\begin{tabular}{ll}
\hline SCENE & \multicolumn{1}{c}{ DESKRIPSI } \\
Pada halaman ini sistem \\
akan menampilakan peta \\
lokasi dari rumah-rumah \\
ibadah berdasarkan \\
kategori yang telah dipilih \\
user dari salah satu fitur \\
yang telah dipilih pada \\
halaman utama tadi.
\end{tabular}

TABEL XII. STORYBOARD TAMPILAN INFORMASI APLIKASI

\begin{tabular}{lll}
\hline \hline SCENE & VISUAL
\end{tabular}

Pada halaman ini sistem sistem akan menampilkan tampilan informasi dari rumah ibadah berdasarkan kategori yang telah dipilih oleh user. Pada tampilan ini akan dimunculkan berupa foto dari rumah ibadah serta informasi mengenai rumah ibadah yang terdiri dari Nama rumah ibadah, Alamat, Jam ibadah, Struktural serta profil singkat mengeni rumah ibadah tersebut. 


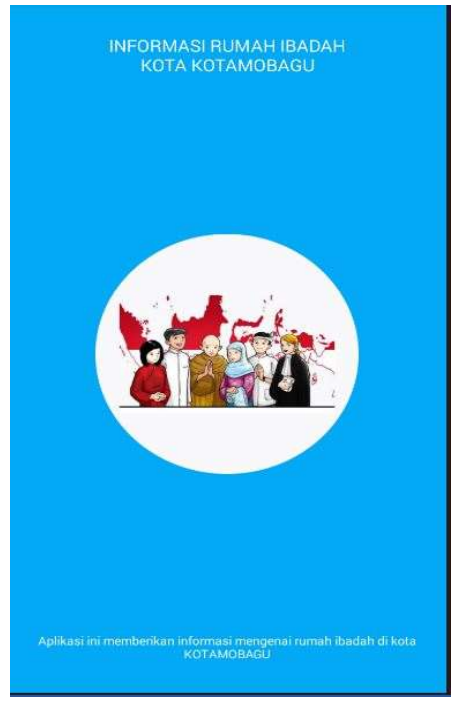

Gambar 7. Tampilan Splashscreen

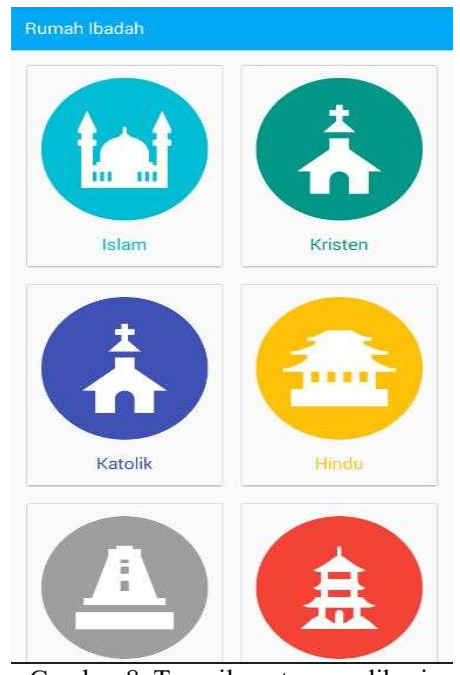

Gambar 8. Tampilan utama aplikasi

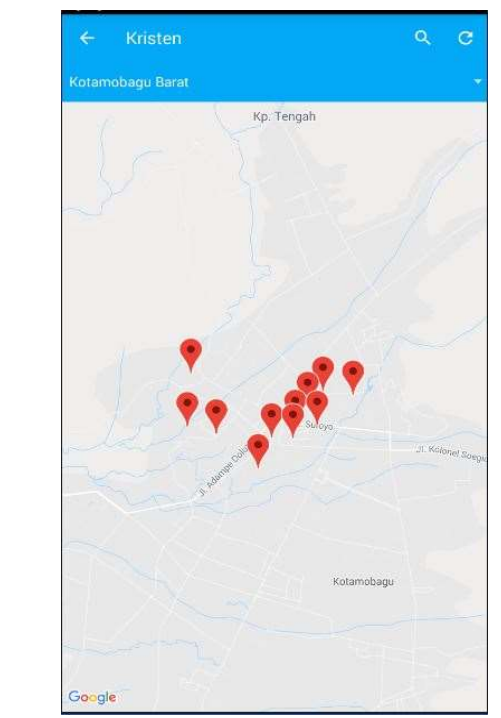

Gambar 9. Tampilan lokasi rumah Ibadah Kristen
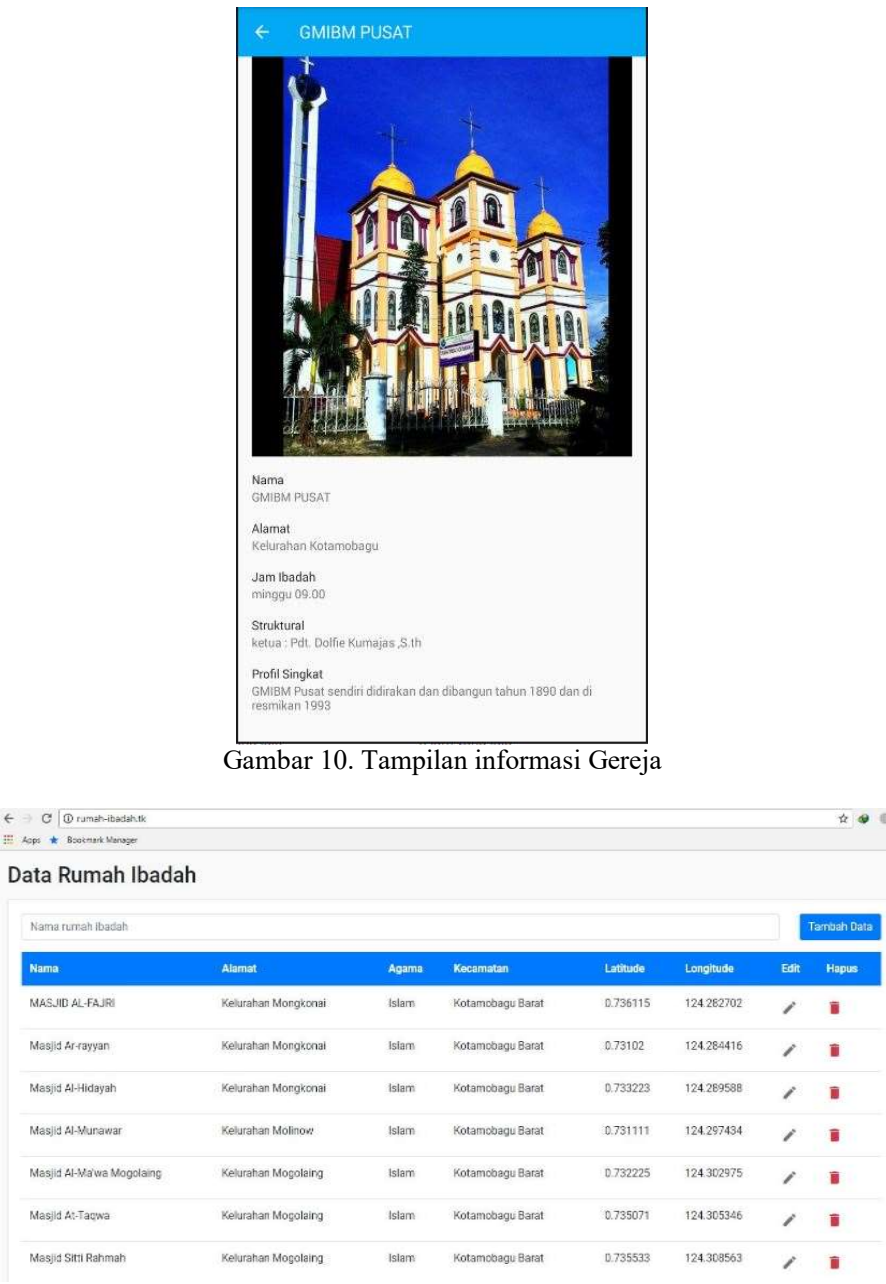

Gambar 11. Tampilan Data Rumah Ibadah

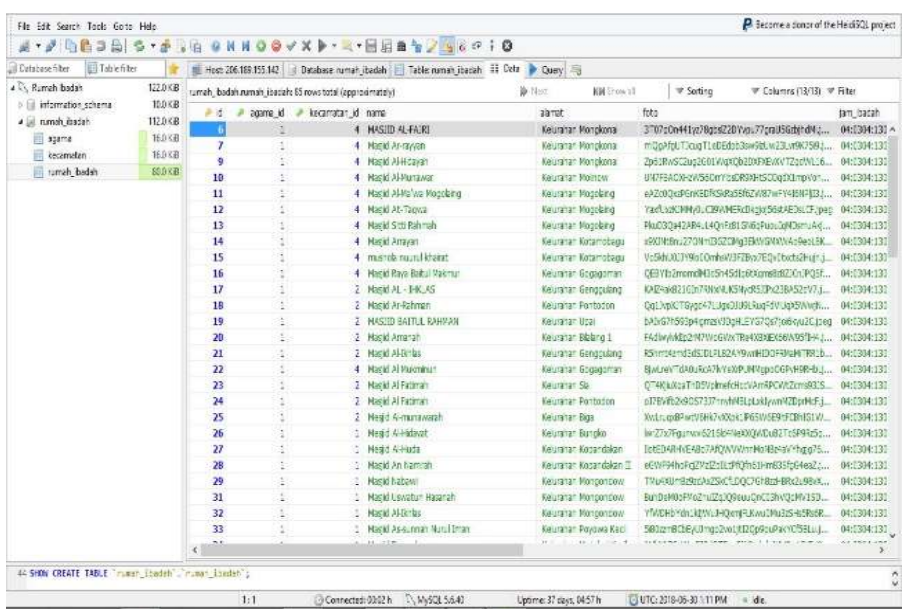

Gambar 12. Tampilan semua data rumah ibadah

Gambar 7 berisikan logo dari aplikasi rumah ibadah dan memberikan informasi singkat mengenai tujuan dari aplikasi rumah ibadah yang merupakan proses Splashscreen yang merupakan tampilan awal sebelum masuk aplikasi.

Gambar 8 merupakan halaman utama dari aplikasi ini,dalam halaman utama ini terdapat beberapa kategori yang akan dipilih oleh user. pada tampilan ini terdiri dari kategori fitur Islam, Kristen, Katolik, Hindu dan Budha. 
Gambar 9 menunjukan ketika user memilih salah satu fitur yang terdapat pada menu utama. Setelah user memilih salah fitur sistem akan menampilkan sebuah halaman baru yang menunjukan lokasi-lokasi dari Gereja yang ada di Kota Kotamobagu. Kemudian apabila user memilih salah satu rumah ibadah yang ada di peta sistem akan menampilkan sebuah informasi tentang rumah ibadah.

Gambar 10 akan muncul ketika kita memilih salah satu kategori yang ada di halaman utama kemudian sistem akan menampilkan titik-titik lokasi rumah ibadah yang ada di kotamobagu. Kemudian apabila user ingin melihat informasi mengenai rumah ibadah user hanya tinggal mengklik titik pointer yang ada pada tampilan lokasi tersebut secara otomatis sistem akan menapilkan sebuah informasi mengenai rumah ibadah tersebut.

Gambar 11 dapat kita lihat bahwa data berhasil diolah dengan baik dimana pada aplikasi ini semua data rumah ibadah dapat ditampilkan. Pada gambar ini dapat kita lihat terdapat beberapa fitur yang disediakan yaitu tambah data yang berfungsi untuk menambahkan data rumah ibadah, edit data untuk memperbaiki apabila ada kesalahan dalam pemasukan nama maupun informasi lainya, dan delete untuk menghapus data rumah ibadah dari aplikasi.

Gambar 14 menampilkan semua data rumah ibadah yang telah berhasil di input dalam aplikasi.

\section{PENUTUP}

\section{A. Kesimpulan}

1) Telah dibuat sebuah aplikasi client berbasis android yang telah berjalan dengan baik sesuai dengan kebutuhan user dengan data dari tiap-tiap rumah ibadah yang diberikan kepada user merupakan sebuah data yang akurat sesuai dengan kebutuhan user.

2) Telah dibuat sebuah aplikasi client berbasis android yang telah berjalan dengan baik sesuai dengan kebutuhan user dengan data dari tiap-tiap rumah ibadah yang diberikan kepada user merupakan sebuah data yang akurat sesuai dengan kebutuhan user.

\section{B. Saran}

Berikut merupakan saran yang berkaitan untuk pengemabangan aplikasi ini kedepan yaitu :

1) Aplikasi yang dibuat dapat dikembangkan dalam bentuk tampilan peta, yaitu dengan menggunakan peta sendiri dan bukan berdasarkan peta dari googlemaps, dan juga dapat dilakukan pengembangan dalam bentuk peta $3 \mathrm{D}$.

2) Lebih dikembangkan agar sistem dapat tetap berjalan saat offline sehingga ketika pengguna berada pada tempat yang tidak dapat terhubung internet aplikasi ini tetap dapat digunakan untuk pencarian rumah ibadah terdekat.

\section{KUTIPAN}

[1] Olii marlon, Rindengan Yaulie, Tuturoong Nancy.2014: Analisa dan perancangan Aplikasi Penilaian dalam Jabatan Struktural di Pemerintahan Kota Manado, Manado e-journal.

[2] Kawulur silvana, Rindengan Yaulie, Karouw Stenly, Robot Jimmy.2013: Perancangan Sistem Informasi Geografis Ruang Terbuka Hijau di Kota Manado,Manado e-journal
[3] Pakpahan Tigor, Rindengan Youlie, Najoan Xaverius.2013: Aplikasi MobilePeta Rawan Bencana Kota Manado Berbasis Android, Manado ejournal.

[4] Christian Nora Eligia, Rindengan Yaulie, Pinrolinvic D. K. Manembu.2016: Rancang Bangun Aplikasi Fasilitas Umum Berbasis Web Service, Universitas Sam Ratulang Manado

[5] W.Ambler,Scott dan Mark Lines.2012 :"Disciplined Agile Delivery A Practioner' Guide to Agile Software Delivery in the Enterprise".

[6] Nazarudin Safaat Harahap. 2012. Pemograman Aplikasi Mobile Smartphone dan Tablet PC Berbasis Android. Informatika. Bandung.

[7] Pressment Roger.2012: Rekayasa Perangkay Lunak, Yogyakarta, Penerbit Andi.

[8] Triyanti Devi Yayuk, Onny Marleen.2014: Aplikasi Android untuk Pencarian Lokasi Tempat Ibadah di Wilayah Bekasi,Universitas Gunadarma,Depok.

[9] Arronoff .S .1989:"'Geographic Information System: A Management Perspective, WDL Publication. Ottawa Canada.

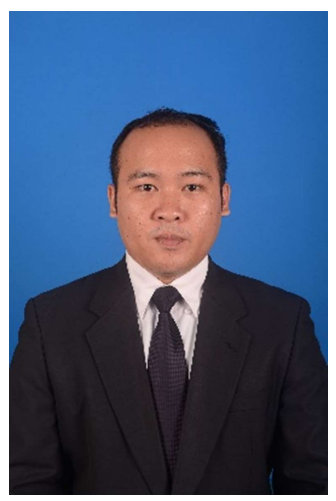

Sekilas tentang penulis Saya bernama Andri Novriadi Lomboan dan merupakan anak kedua dari pasangan Jantje Frits Lomboan dan Aneke Tineke Manapa, lahir di Kotamobagu pada tanggal 04 November 1993.

Saya mulai menempuh pendidikan di Sekolah Dasar Negeri 3 Kotamobagu (1999-2005). Kemudian melanjutkan studi tingkat pertama di SMP Negeri 1 Kotamobagu (20052008). Selanjutnya saya menempuh pendidikan tingkat atas di SMK Cokroaminto Kotamobagu (2008-2011).

Setelah itu, di tahun 2011 saya melanjutkan pendidikan ke salah satu perguruan tinggi yang berada di Kota Manado yaitu Universitas Sam Ratulangi Manado, dengan mengambil Program Studi S-1 Teknik Informatika di Jurusan Elektro Fakultas Teknik. Selama masa kuliah penulis pernah tergabung dalam kepengurusan organisasi Himpunan Mahasiswa Elektro periode 2014 sampai 2015 pada kepengurusan tersebut penulis tergabung dalam Sie Sarana dan Prasarana . Pada bulan Februari tahun 2018,penulis membuat Skripsi demi memenuhi syarat Sarjana(S1) dengan penelitian berjudul Rancang Bangun Aplikasi Pencarian Rumah Ibadah di Kotamobagu Berbasis Android yang di bimbing oleh dua dosen pembimbing yaitu Dringhuzen J. Mamahit, ST,. M.Eng dan Yauilie Deo Y.Rindengan,ST ,.M.Sc,.MM

Pada bulan Agustus 2018, penulis dinyatakan lulus melalui Sidang Tertutup Program Studi Teknik Informatika, Universitas Sam Ratulangi, dengan menyandang gelar Sarjana Komputer (S.Kom). 